\title{
Sosialisasi Dan Pelatihan Badan Usaha Milik Negeri Lowpano Sebagai Penyokong Kemandirian Negeri Tehua
}

\author{
Resa Dandirwalu1 ${ }^{1}$ \\ Fakultas Teologi Universitas Kristen Indonesia Maluku, resadandirwalu@ukim.ac.id \\ Grace Persulessy² \\ Fakultas Ekonomi Universitas Kristen Indonesia Maluku, persulessygrace@gmail.com \\ Ivander Hutubey ${ }^{3}$ \\ Fakultas Teologi Universitas Kristen Indonesia Maluku, ihutubessy@yahoo.com \\ Gloria H. Wacanno ${ }^{4}$ \\ Fakultas Teologi Universitas Kristen Indonesia Maluku, wacannog@gmail.com \\ Nilam Sari ${ }^{5}$ \\ Fakultas Ekonomi Universitas Kristen Indonesia Maluku, nilamsari@gmail.com \\ Diana K. E. Putri ${ }^{6}$ \\ Fakultas Teologi Universitas Kristen Indonesia Maluku, dkeren911@gmail.com \\ Filders J. Latuputty ${ }^{7}$ \\ Fakultas Teologi Universitas Kristen Indonesia Maluku, fildersl@gmail.com
}

\begin{abstract}
Abstrak
Pengabdian kepada Masyarakat yang dilakukan oleh Tim dengan Mitra bertolak pada permasalahan prioritas yang disepakati antara Tim dengan Mitra, yaitu belum adanya pengetahuan dan ketrampilan dari mitra tentang Manajemen Badan Usaha Milik Negeri yang baik dan berkualitas, dengan tujuan adalah peningkatan pengetahuan dan ketrampilan mitra tentang Manajemen BUMNeg yang berkualitas dan peningkatan ketrampilan mitra untuk mempraktekan Manajemen BUMNeg yang berkualitas dalam Manajemen Badan Usaha Milik Negeri Lowpano. Karena itu, Tim melakukannya dalam tiga tahapan, yaitu: (1) tahapan persiapan, adalah tahap pembentukan Tim, identifikasi mitra, wawancara, dan analisis kebutuhan, (2) tahapan pelaksanaan, adalah tahapan memberikan pengetahuan dan ketrampilan tentang Manajemen Badan Usaha Milik Negeri kepada Mitra, dan (3) tahapan evaluasi dan tindak lanjut, adalah tahapan mengevaluasi dan tindak lanjut dari kegiatan yang dilakukan. Hasil yang diperoleh adalah Pengetahuan dan ketrampilan Mitra meningkat dari 25 persen menjadi 80 persen tentang Manajemen Manajemen Badan Usaha Milik Negeri yang baik dan berkualitas, agar Mitra dapat menggunakan dan mengimplementasi Manajemen tersebut dalam BUMNeg Lowpano, sehingga dapat menjadi penyokong terciptanya kemandirian Negeri Tehua.
\end{abstract}

Kata Kunci: Badan Usaha Milik Negeri Lowpano; Manajemen; Mitra; Negeri Tehua; Sosialisasi

\begin{abstract}
The community service which was done by team and partner departs from the agreed priority issues between the team and the partner that is the lack of knowledge and skills of partners regarding good and qualified management of village-owned enterprise. The goal is to increase partners' knowledge and skills regarding the quality of management of village-owned
\end{abstract}


enterprise and to improve their skills to implement that qualified management into management of Lowpano village-owned enterprise. Then the team did the service in three phases, they are: 1) the preaparation which was divided to composing the team, identifying partners, interviewing, and analyzing the needs. 2) The realization phase where the partners were provided with knowledges and skills of management of village-owned enterpises, and 3) the evaluation and follow-up phase. Here the activities were evaluation and the follow-up of the activities were determined. The obtained result was the knowledge and the skill of the partners increased from $25 \%$ to $80 \%$ on the good and qualified management of state-owned enterprise then the partner might apply and implement the management to management of Lowpano village-owned enterprise so that it could support the self-sustaining of Tehua Village.

Keywords: The Village-owned Enterprise Lowpano; Management; Partner; Tehua Village; Socialization

\section{Pendahuluan}

Setiap Desa/Negeri di Indonesia memiliki visi untuk meningkatkan dan mengembangkan ekonomi masyarakat negerinya, maka diperlukan Badan Usaha Milik Desa/Negeri sebagai wadah perwujudan visi dimaksud, melalui UU No.32 Tahun 2004 (Sofyan, 2015), tentang Pemerintahan Daerah; dan UU No.6 Tahun 2014, tentang Desa (Nilawaty, 2018). Karena itu, Badan Usaha Milik Desa, adalah badan usaha yang seluruh atau sebagian besar modalnya dimiliki oleh Desa melalui penyertaan secara langsung yang berasal dari kekayaan Desa yang dipisahkan untuk mengelola aset, jasa pelayanan, dan usaha lainnya untuk sebesar-besarnya kesejahteraan masyarakat Desa (Novandi, 2019).

Berdasarkan UU No.32 Tahun 2004 dan UU No.6 Tahun 2014 tersebut, maka Pemerintah Negeri Tehua membentuk Badan Usaha Milik Neger (BUMNeg) Lowpano (Bahasa Alune: Low, artinya loko atau pegang dan Pano artinya ulu parang, sehingga Lowpano artinya pegang ulu parang), melalui Peraturan Negeri Tehua No. 06 Tahun 2018, tentang Pembentukan dan Pengelolaan Badan Usaha Milik Negeri (BUMNeg) Lowpano. Pembentukan BUMNeg, diikuti dengan Surat Keputusan Kepala Pemerintah Negeri Tehua No. 12 Tahun 2018, tentang Pengangkatan Susunan Organisasi Pengelolaan BUMNeg Lowpano Negeri Tehua, dengan jumlah 18 orang, sebagai berikut: Penasehat: Raja Negeri Tehua; Badan Pelaksana Operasional: Syarif Ode; Direktur: Ibrahim Latua; Sekertaris: Munasir Tehuayo; Bendahara: Nursin Tehuayo; Badan Pengawas. Ketua: Moksin Tehuayo; Wakil Ketua: Ahmad Latua; Sekretaris: Fadlan Latua; Anggota: Bakri Usemahu; Anggota: Lutfi Tehuayo; Unit Usaha Pengembangan Perikanan dan Kelautan. Ketua Bidang: Umar Hayoto; Anggota: Laruki. Unit Usaha Bidang Pariwisata. Ketua Bidang: Johan Kabalmai; Anggota: Nurbaya Yanglera. Unit Usaha Simpan Pinjam dan Aneka Jasa. Ketua Bidang: Jalima Tehuayo; Anggota: Jaima Usemahu. Unit Usaha Pertukangan dan Bangunan. Ketua Bidang: Jufri Roroa; Anggota: Yasri Roroa.

Badan Usaha Milik Negeri (BUMNeg) Lowpano Negeri Tehua, berada di Negeri Tehua, Kecamatan Telutih, Kabupaten Maluku Tengah, Provinsi Maluku, sehingga 
secara geografis sebelah Utara berbatasan dengan Hutan Lindung, sebelah Selatan berbatasan dengan Laut Banda, sebelah Timur berbatasan dengan Negeri Maneoratu, dan sebelah Barat berbatasan dengan Negeri Lafa, sedangkan penduduknya berjumlah 2914 jiwa, yang terbagi dalam 11 RT, dan sebagian besar hanya menamatkan Sekolah Dasar, serta bermata pencaharian sebagai Petani.

Badan Usaha Milik Negeri (BUMNeg) Lowpano Negeri Tehua memiliki visi yaitu: mewujudkan kesejahteraan masyarakat Negeri Tehua melalui pengembangan usaha ekonomi, Perikanan, Pertanian, pelayanan sosial dan pariwisata; dan misi yaitu: Pengembangan usaha ekonomi melalui usaha simpan pinjam dan usaha sektor riil; Pengembangan usaha Perikanan dan pertanian melalui pemanfaatan potensi yang tersedia di Negeri; Pembangunan layanan sosial melalui sistem jaminan sosial bagi rumah tangga miskin; Pengembangan usaha parwisata melalui pemanfaatan potensi parwiwisata yang ada di Negeri; Pembangunan infrastruktur dasar Negeri yang mendukung perekonomian di Negeri; Mengembangkan jaringan kerjasama ekonomi dengan berbagai pihak; Mengelola dana program yang masuk ke Negeri bersifat dana bergulir terutama dalam rangka pengentasan kemiskinan dan pengembangan usaha ekonomi di Negeri.

Badan Usaha Milik Negeri (BUMNeg) Lowpano Negeri Tehua, sebagai mitra kegiatan Pengabdian Kepada Masyarakat memiliki berbagai permasalahan antara lain belum memiliki gedung untuk dijadikan seluruh aktivitas perkantoran, sehingga selalu disesuaikan dengan aktivitas yang berlangsung di Kantor Negeri Tehua.

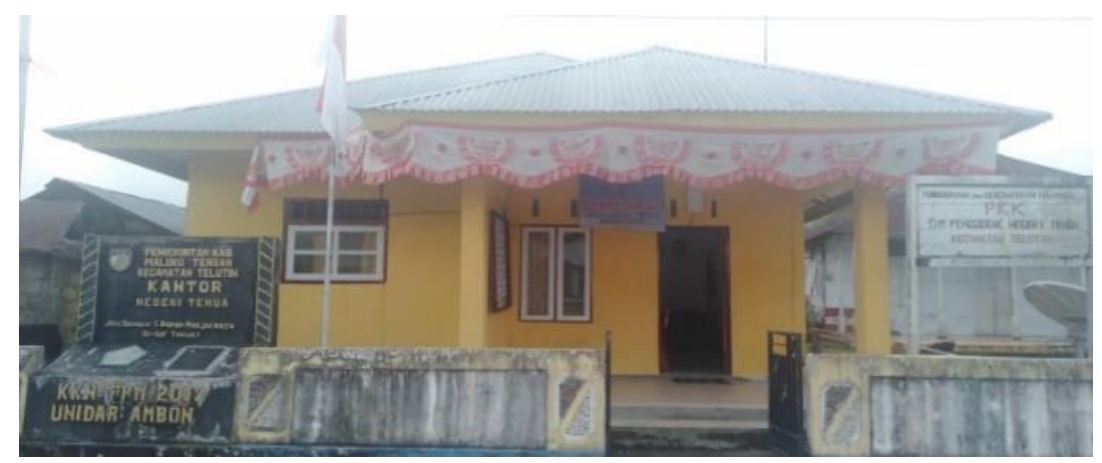

Sumber: Dokumen Tim PKM UKIM, 2019

Gambar 1. Kantor Desa tempat perkantoran BUMNeg Lowpano

Sebagian pengurus BUMNeg Lowpano hanya menamatkan pendidikan pada tingkat Sekolah Menengah Atas (SMA), sehingga sangat terbatas dari segi kualitas Sumber Daya Manusia, meskipun begitu mereka tetap berusaha untuk beraktivitas menghidupkan BUMNeg Louwpano; selain itu, Pengurus BUMNeg Lowpano belum pernah diberikan pengetahuan yang memadai tentang manajemen yang baik dalam mengelola BUMNeg Lowpano; Manajemen pembukuan yang dipergunakan selama ini masih sangat sederhana, karena hanya mencatat pemasukan dan pengeluaran tanpa melalui suatu rancangan anggaran yang sistematis dan teranalisis terlebih dahulu, sehingga sulit untuk mengukur dan mengevaluasi perkembangan keuangan yang dimiliki oleh BUMNeg Lowpano; bidang usaha yang selama ini 
dikembangkan oleh BUMNeg Lowpano hanyalah memberikan pinjaman kepada masyarakat untuk berusaha, dengan suku bunga disesuaikan berdasarkan jumlah pinjaman, sehingga BUMNeg Lowpano selalu mengalami devisit karena angsuran pinjaman yang disetor oleh masyarakat mengalami kesulitan.

Berdasarkan hasil wawancara dengan Bapak Ibrahim Latua (Direktur BUMNeg Lowpano) dan Bapak Hasan Tehuayo (Raja Tehua), maka disepakati secara bersamasama antara Mitra dengan Tim bahwa masalah prioritas yang dihadapi adalah Manajemen BUMNeg Lowpano, yaitu: Belum adanya pengetahuan dan ketrampilan dari mitra tentang Manajemen BUMNeg yang baik dan berkualitas. Karena itu, solusi menjadi penting untuk mengatasi permasalahan mitra, yaitu: Memberikan pengetahuan dan ketrampilan kepada mitra tentang Manajemen BUMNeg Lowpano yang baik dan berkualitas, karena manajemen selalu berhubungan dengan pengambilan kebijaksanaan, koordinasi, dan kepemimpinan (Mirrian, 2014), kemudian pengorganisasian yang baik dan berkualitas dapat berdampak positif terhadap organisasi, mulai dari sistem kerja, struktur, sumber daya hingga aspek lainnya (Rachman, 2015). Agar Manajemen BUMNeg Lowpano dapat tercipta di Mitra, maka diperlukan pemahaman dan ketrampilan terhadap Manajemen, karena pemahaman dan pelatihan merupakan strategi atau solusi untuk terciptanya Manajemen yang baik dan bertanggung jawab, sehingga prinsip-prinsip manajemen berstandar dapat tercapai, seperti manajemen perencanaan, pengorganisasian, personalia, kepemimpinan, dan pengawasan (Ermatati dkk, 2018).

\section{Metode}

Solusi terhadap masalah yang dialami mitra dapat dilihat pada tabel 1 di bawah,

Tabel 1. Solusi Permasalahan

\begin{tabular}{|c|c|c|c|c|}
\hline $\begin{array}{c}\text { Bidang } \\
\text { Masalah }\end{array}$ & Permasalahan Mitra & Solusi & Kegiatan & $\%$ \\
\hline \multirow[b]{2}{*}{$\begin{array}{c}\text { Ekono } \\
\text { mi }\end{array}$} & $\begin{array}{l}\text { Belum adanya } \\
\text { pengetahuan yang } \\
\text { memadai dari mitra } \\
\text { tentang Manajemen } \\
\text { BUMNeg yang baik dan } \\
\text { berkualitas }\end{array}$ & $\begin{array}{l}\text { Memberikan } \\
\text { pengetahuan yang } \\
\text { memadai kepada } \\
\text { mitra tentang } \\
\text { Manajemen } \\
\text { BUMNeg yang baik } \\
\text { dan berkualitas }\end{array}$ & $\begin{array}{l}\text { Sosialisasi } \\
\text { tentang } \\
\text { Manajemen } \\
\text { BUMNeg yang } \\
\text { baik dan } \\
\text { berkualitas }\end{array}$ & $\begin{array}{l}\text { Peningkatan } \\
\text { pengetahuan } \\
\text { mitra tentang } \\
\text { Manajemen } \\
\text { BUMNeg yang } \\
\text { baik dan } \\
\text { berkualitas, } \\
\text { mencapai } 80 \%\end{array}$ \\
\hline & $\begin{array}{lr}\text { Belum } & \text { adanya } \\
\text { ketrampilan } & \text { yang } \\
\text { memadai dari mitra } \\
\text { tentang Manajemen } \\
\text { BUMNeg Lowpano yang } \\
\text { baik dan berkualitas. }\end{array}$ & $\begin{array}{l}\text { Memberikan } \\
\text { ketrampilan yang } \\
\text { memadai kepada } \\
\text { mitra tentang } \\
\text { Manajemen } \\
\text { BUMNeg yang baik } \\
\text { dan berkualitas }\end{array}$ & $\begin{array}{l}\text { Pelatihan dan } \\
\text { praktek tentang } \\
\text { Manajemen } \\
\text { BUMNeg yang } \\
\text { baik dan } \\
\text { berkualitas }\end{array}$ & $\begin{array}{l}\text { Peningkatan } \\
\text { ketrampilan } \\
\text { mitra untuk } \\
\text { mempraktekan } \\
\text { Manajemen } \\
\text { BUMNeg yang } \\
\text { baik dan } \\
\text { berkualitas, } \\
\text { mencapai } 80 \%\end{array}$ \\
\hline
\end{tabular}


Solusi di atas dilakukan melalui kegiatan Pengabdian kepada Masyarakat yang dilakukan dalam 4 tahapan, yaitu: 1) Tahapan Persiapan; 2) Tahapan Pelaksanaan;

3) Tahapan Evaluasi dan Tindak Lanjut.

A. Tahapan Persiapan

Tahapan Persiapan ini terdiri dari empat (4) tahapan, yang tergambar pada gambar 1 di bawah ini, yaitu: Pembentukan Tim, Identifikasi Mitra, Wawancara, dan Analisis Kebutuhan Mitra

B. Tahapan Pelaksanaan

Tahapan Pelaksanaan terdiri dari dua (2) tahap, yaitu: Memberikan Pengetahuan tentang Manajemen BUMNeg, dan Memberikan Ketrampilan tentang Manajemen BUMNeg

C. Tahapan Evaluasi dan Tindak Lanjut

Tahapan Evaluasi dan Tindak Lanjut terdiri dari satu (1) tahapan, yaitu: Evaluasi Kegiatan dan Tindak Lanjut.

Kegiatan Pengabdian kepada Masyarakat tersebut, berlangsung dengan mitra, yaitu: BUMNeg Lowpano di Negeri Tehua, dari tanggal 11 hingga 22 September 2019.

\section{Hasil dan Pembahasan}

\section{A. Tahap Persiapan}

Kegiatan awal Pengabdian kepada Masyarakat adalah Pembentukan Tim yang terdiri dari dosen dan mahasiswa, sehingga terbentuklah Tim yang terdiri dari 2 orang Dosen (R. Dandirwalu dan Grace Persulessy) dan 5 orang Mahasiswa (Filders Latuputty, Gloria Wacanno, Nilam Sari, Diana Eka Putri, dan Ivander Hutubessy). Tim melakukan diskusi untuk mengidentifikasi Mitra yang akan menjadi lokasi tempat melakukan Pengabdian kepada Masyarakat, sehingga dipilih Negeri Tehua, khususnya Badan Usaha Milik Negeri Lowpano Negeri Tehua.

Tim berkunjung dan tinggal di Negeri Tehua mulai dari tanggal 11 hingga 22 September, untuk melakukan observasi terhadap aktivitas yang dilakukan oleh Pengurus BUMNeg Lowpano dan wawancara dengan Direktur BUMNeg Lowpano serta Raja Tehua. Berdasarkan observasi dan wawancara tersebut, disepakati bahwa permasalahan utama yang sedang dihadapi oleh BUMNeg Lowpano adalah belum adanya pengetahuan dan ketrampilan dari Pengurus tentang Manajemen BUMNeg yang baik dan berkualitas, sehingga diperlukan pengetahuan dan ketrampilan kepada mitra tentang Manajemen BUMNeg Lowpano yang baik dan berkualitas, maka Tim bersepakat dengan Mitra untuk melakukan kegiatan sosialisasi dan pelatihan kepada Pengurus BUMNeg tentang Manajemen BUMNeg, yang berlangsung pada hari Jumat, 20 September 2019, Jam 08.00 - 15.00 WIT, di Kantor Negeri Tehua.

\section{B. Tahap Pelaksanaan}

Pelaksanaan kegiatan Tim dengan mitra terdiri dari 2 kegiatan, yaitu kegiatan sosialisasi dan pelatihan, yaitu: 


\section{Sosialisasi}

Kegiatan sosialisasi berlangsung pada hari Jumat, 20 September 2019, Jam 08.00-12.00 WIT, di Kantor Negeri Tehua, yang diikuti oleh 50 orang peserta, yang terdiri dari unsur Pengurus BUMNeg, PKK, Tokoh Adat, Tokoh Agama, Saniri Negeri, Aparat Negeri, Perwakilan Siswa/I SMA, dan Perwakilan Masyarakat.

Kegiatan sosialisasi diawali dengan Pembukaan yang dilakukan oleh Raja Negeri Tehua dan berdoa oleh Mahasiwa, yang berlangsung selama 30 menit, kemudian dilanjutkan dengan pre-test untuk mengukur pemahaman awal peserta tentang Manajemen BUMNeg, dan hasilnya adalah 25 persen peserta memiliki pemahaman awal yang cukup rendah tentang Manajemen BUMNeg.

Materi sosialisasi Manajemen BUMNeg mengedepankan perkembangan BUMDes di Indonesia yang memperlihatkan 93,75 persen belum berjalan dengan baik, dilanjutkan dengan berbagai aturan dasar pembentukan BUMDes disertai dengan filosofis dan struktur BUMDes, kemudian konsep tentang manajemen untuk pengelolaan BUMDes yang baik, transparan dan akuntabel, serta memperhatikan aspek perencanaan, pengorganisasian, personalia, kepemimpinan, dan pengawasan. Selain itu, materi diakhiri dengan contoh keberhasilan dari Manajemen BUMDes Kampoeng Mataraman di Desa Panggungharjo, sehingga keberhasilan dari BUMNeg Lowpano sangat dipengaruhi oleh Manajemen yang baik dan berkualitas, agar visi dan misi yang ditetapkan dapat tercapai, dan berdampak positif pada kesejahteraan masyarakat di Negeri Tehua.

Selama proses penyajian materi, tampak antusias yang tinggi ditunjukan oleh peserta melalui kesediaan mereka untuk menyimak dan mendengar dari awal hingga akhirnya materi disampaikan, dan adanya respons positif dari peserta yang ditunjukan melalui pertanyaan dan komentar yang disampaikan oleh peserta, bahkan harapan dari peserta agar kegiatan seperti ini perlu dilanjutkan, seperti tampak pada gambar 2 di bawah ini.

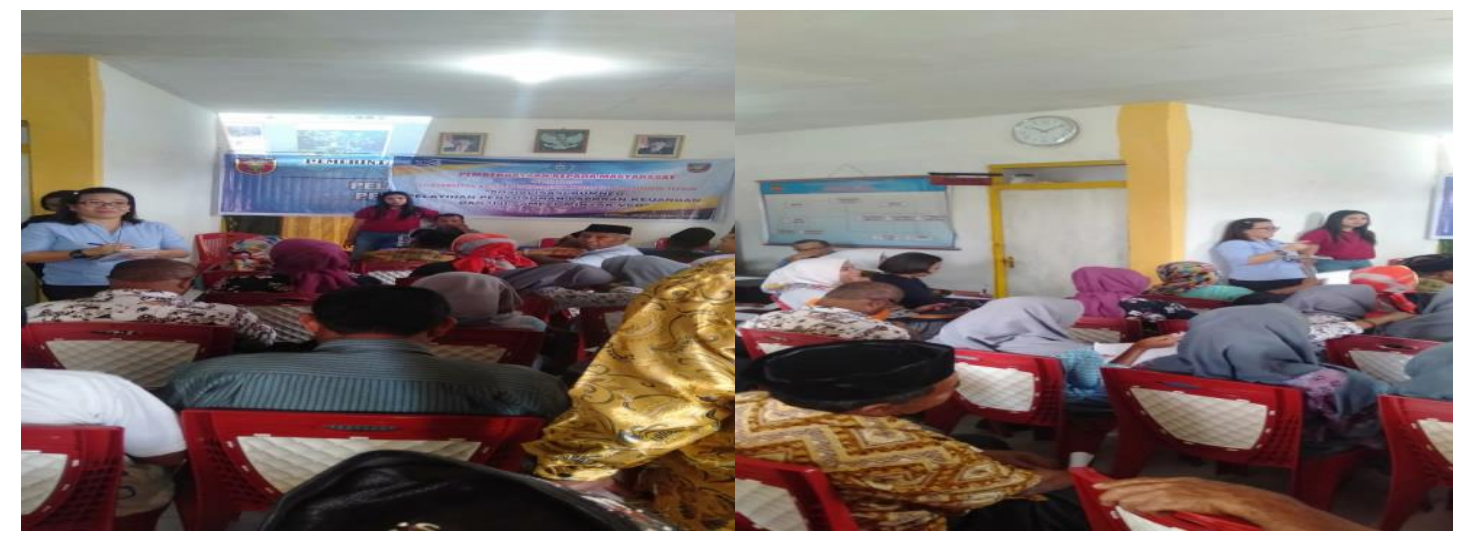

Sumber: Dokumen Tim PKM UKIM, 2019

Gambar 2. Penyajian Materi tentang Manajemen BUMNeg

Sesudah berakhirnya kegiatan sosialisasi, Tim melakukan post-test kepada peserta dengan menggunakan pertanyaan sejenis pada pre-test, sebagai bentuk evaluasi untuk mengukur ketercapaian materi yang disampaikan, dan hasilnya adalah 80 persen pemahaman peserta sangat baik tentang Manajemen BUMNeg dibandingkan 
dengan pre-test yang hanya 25 persen, sehingga tampak bahwa melalui kegiatan sosialisasi yang dilakukan oleh Tim tentang Manajemen BUMNeg kepada peserta, memberikan hasil yang cukup baik karena terjadi peningkatan pemahaman.

\section{Pelatihan}

Sesudah kegiatan sosialisasi tentang manajemen BUMNeg, maka dilanjutkan dengan pelatihan manajemen BUMNeg, yang berlangsung pada hari Jumat, 20 September 2019, Jam 13.00 - 15.00 WIT, di Kantor Negeri Tehua, yang diikuti oleh 50 orang peserta, yang terdiri dari unsur Pengurus BUMNeg, PKK, Tokoh Adat, Tokoh Agama, Saniri Negeri, Aparat Negeri, Perwakilan Siswa/I SMA, dan Perwakilan Masyarakat.

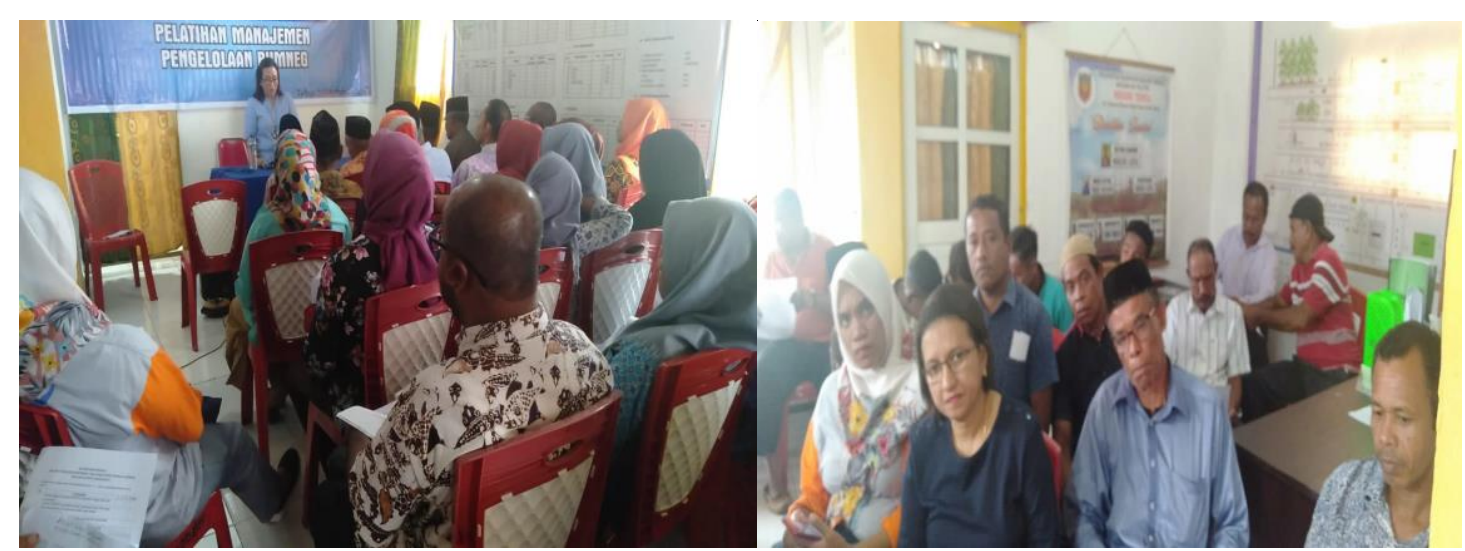

Sumber: Dokumen Tim PKM UKIM, 2019

Gambar 3.Pelatihan Manajemen BUMNeg

Pelatihan Manajemen BUMNeg Lowpano berlangsung dengan mekanisme sebagai berikut: peserta diberikan kesempatan berlatih untuk menyusun program tahunan yang inovatif, anggaran untuk tahun 2019, dan rencana kerja, karena ketiga hal inilah yang selalu menjadi aktivitas dari BUMNeg Lowpano, dengan waktu yang diberikan adalah 60 menit untuk peserta bekerja, sambil tim mendampingi dan memberikan masukan, sehingga memudahkan mereka menyelesaikannya.

Peserta bekerja secara individu, karena ruangan pelatihan sangat terbatas, sehingga proses kerja secara kelompok tidak bisa dilakukan, namun peserta tidak keberatan. Sebaliknya, mereka sangat serius mengerjakan tugas yang sedang diberikan, sehingga ada yang mengerjakannya dilembaran kertas HVS, dan ada yang kerja di laptop, dan sesudah 60 menit, 3 peserta menjadi perwakilan untuk menyampaikan hasilnya dan ditanggapi oleh fasilitator. Berdasarkan hasil persentasi tersebut, tampak bahwa peserta sudah bisa membuat program tahunan yang inovatif, anggaran untuk tahun 2019, dan rencana kerja yang baik, sehingga fasilitator memberikan tanggapan positif terhadap hasil kerja yang dipresentasi tersebut, dengan memberikan harapan agar mereka tetap mengimplentasinya dalam pengelolaan BUMNeg Lowpano, sehingga dapat berdampak pada kemajuan dan 
perkembangan BUMNeg ke depan, dan keberadaan BUMNeg Lowpano dapat menjadi penyokong tercapainya kemandirian Negeri Tehua.

\section{Evaluasi dan Tindak Lanjut}

Kegiatan sosialisasi dan pelatihan Manajemen di BUMNeg Lowpano dikatakan berhasil, karena berdasarkan hasil evaluasi dengan mitra, mereka memandang bahwa kegiatan sosialisasi dan pelatihan tentang Manajemen BUMNeg yang diikuti memberikan kontribusi yang tinggi dan memuaskan karena baru pertama kali diikuti, maka informasi yang belum pernah diperoleh sebelumnya dapat diketahui dengan baik dan benar. Karena itu, tindak lanjut dari kegiatan ini adalah kerjasama dan komunikasi terus terbina antara Tim dengan Mitra melalui perjumpaan di Negeri Tehua dan jaringan seluler (HP), agar BUMNeg Lowpano semakin berkualitas dalam menjalankan Manajemen BUMNeg Lowpano, agar sesuai dengan standar manajemen.

\section{Simpulan dan Rekomendasi}

Sesudah pelaksanaan kegiatan sosialisasi dan pelatihan melalui Pengabdian kepada Masyarakat, maka kesimpulannya adalah pertama, peserta sosialisasi mengalami peningkatan wawasan atau pengetahuan yang baik dan berkualitas tentang Manajemen BUMNeg, untuk memanfaatkannya dalam pengelolaan BUMNeg Lowpano; dan kedua, peserta sosialisasi semakin terampil dalam menggunakan Manajemen pada BUMNeg, sehingga dapat mengimplmentasikan dalam BUMNeg Lowpano.

\section{Acknowledgements}

Tim menyampaikan terima kasih yang sebesar-besarnya kepada Lembaga Pengabdian Masyarakat Universitas Kristen Indonesia Maluku yang boleh memberikan anggaran, sehingga kegiatan Pengabdian boleh terlaksana dengan kelompok mitra, yaitu BUMNeg Lowpano di Negeri Tehua; selain itu, tim menyampaikan terima kasih kepada mitra yang bersedia menyiapkan tempat dan peserta, sehingga kegiatan pengabdian boleh berlangsung dengan baik.

\section{Daftar Pustaka}

Arif Mirrian Sjofjan, Hubungan Antara Administrasi, Organisasi, dan Manajemen. http:// repository.ut.ac.id/3959/1/ADPU4217-M1.pdf

Hatta Ermatati, Rangga Putra Ananto, Armel Yentifa, Ulfi Maryati, Dita Maretha Rissi. Pelatihan Dan Pembenahan Manajemen Keuangan Dan Administrasi Pada Yayasan PAUD Dan TK Musa Enda Padang. Jurnal Akuntansi \& Manajemen. Vol 13, No. 2 - 2018, 17-24. ejournal2.pnp.ac.id > jam > article > download

Novandi Harod Rahmad dan Isbandi Rukminto Adi . Badan Usaha Milik Desa (BUMDes) Ijen Lestari Sebagai Inovasi Pelayanan Publik Untuk Mendukung 
Pengembangan Ekonomi Lokal Melalui Community Based Tourism. Jurnal Ilmu Kesejahteraan Sosial, Jilid 20, Nomor 1, April 2019. jurnalkesos.ui.ac.id > jiks > article > download

Nilawaty Evi. Analisis Manajemen Badan Usaha Milik Desa (BUMDesa)

"Hanyukupi" Desa Ponjong Kecamatan Ponjong Kabupaten Gunungkidul.

Jurnal Wacana Kinerja. Volume 21, Nomor 1, Juni 2018.

https://www.researchgate.net/publication/328057567_Analisis_Manajemen_Ba dan_Usaha_Milik_Desa_BUMDESA_Hanyukupi_Desa_Ponjong_Kecamatan_Po njong_Kabupaten_Gunungkidul

Rachman Fathor. Manajemen Organisasi Dan Pengorganisasian Dalam Perspektif AL-QUR'AN Dan HADITH. Jurnal "Ulûmunâ : Jurnal Studi Keislaman Vol.1 No.2 Desember 2015 : ISSN 2442-8566. ejournal.kopertais4.or.id > ulumuna > article > download

Sofyan Ahmad. 2015. Badan Usaha Standard dan Peraturan. http://www.keuangandesa.com/2015/09/landasan-hukum-pendirian-badanusaha-milik-desa/ 